\title{
Toksoplazmozis Kedilerde Davranışsal Değişikliklere Neden Olabilir mi?
}

\author{
Didem Pekmezci', Gökmen Zafer Pekmezci \\ ${ }^{1}$ Ondokuz Mayıs Üniversitesi Veteriner Fakültesi İ̧̧ Hastalıkları Anabilim Dalı Samsun \\ ${ }^{2}$ Ondokuz Mayıs Üniversitesi Veteriner Fakültesi Klinik Öncesi Bilimler Bölümü Samsun
}

Geliş Tarihi / Received: 12.10.2016, Kabul Tarihi / Accepted: 03.11.2016

\begin{abstract}
Özet: Toksoplasmozis dünyada memeli ve kanatlı türlerini etkileyen ve Toxoplasma gondii tarafından oluşturulan son konağ1 kedigiller olan sistemik protozoon enfeksiyonudur. Dünya genelinde evcil kedilerde (Felis catus) seroprevalansın \%30-40 arasında olduğu tahmin edilmektedir. İnsanlarda parazitin oluşturduğu problemler açıkça bilinmektedir. Bununla birlikte kedilerde parazitin beyin, spinal kord, göz, akciğer, karaciğer, kalp, iskelet kası, dil, adrenal bez ve böbrek gibi hayati organlarda lezyonlar şekillendirdiği ortaya konulmuştur. Ancak, parazitin kedilerde davranışsal değişikliğe neden olup olmadığ incelenmemiştir. Bu derleme ile T. gondii'nin kedilerde insanlardakine benzer davranışsal değişikliklere neden olup olmadığının araştırılması konusuna katkı sunulacağı kanaatindeyiz.
\end{abstract}

Anahtar kelimeler: Kedi, Toksoplazmozis, Davranışsal değişiklikler

\section{Can Toxoplasmosis Make Behavioural Alterations in Cats?}

\begin{abstract}
Toxoplasmosis is a protozoan infection, whose definitive host is cats, can affect mammals and avian population whole around the world. It is thought that the seroprevelence among the domestic cats (Felis catus) is 30-40\% in all over the world. As an intermediate host, problems are all clearly reported in human beings. The parasite can make problems in brain, spinal cord, eyes, lung, liver, heart, muscle, tongue, adrenal glands and kidneys in cats as both an intermediate and definitive host. But behavioral alterations are not investigated in cats. Within the present review it is aimed to guide researchers on new topics about possible roles of toxoplasmosis in behavioral alterations in cats same as seen in human beings.
\end{abstract}

Key words: Cat, Toxoplasmosis, Behavioural alterations

\section{Giriş}

Toksoplasmozis dünyada memeli ve kanatlı türlerini etkileyen ve Toxoplasma gondii tarafindan oluşturulan sistemik protozoon enfeksiyonudur. Kediler ve diğer Felidae türleri $T$. gondii'nin hem ara hem de tek ve son konaklarıdır. Ara konak ise insan dâhil olmak üzere birçok memeli ve kanatlı hayvandır $[15,43]$. Kedilerde parazitin şizogoni ve gametogoni evrelerini geçirdiği intestinal form şekillenirken herhangi bir klinik bulgu dikkati çekmez. Kedilerde ancak konak direncinin zayıfladığı durumlarda ölümcül sistemik toksoplazmoz şekillenebilmektedir $[15,28,29]$. Konak parazit ilişkisini konak ve parazite ait genetik faktörler, konağın yaşı, etkenin gelişim aşamasına ait antijenik çeşitlilik ve enfeksiyon dozu gibi kriterler belirler [20]. Birçok konakta başarılı bir şekilde morfolojik formlarını oluşturabilen $T$. gondii ilk olarak Nicolle ve Manceaux tarafından 1908 yılında Kuzey Afrika'da yaşayan bir kemirgen olan Gundii'nin böbrek ve karaciğerlerin- de bulunmuştur. Nicolle ve Manceaux tarafindan Toxoplasma genusu tanımlanmış ve tek tür olarak da T. gondii bildirilmiştir [11]. İlk insan olgusu 1923 y1lında Prag'lı bir oftalmolog olan Janku tarafindan konjenital hidrosefali ve mikroftalmili bir bebeğin retinasında kistlerin bulunması ile rapor edilmiştir. Türkiye' de ilk insan olgusu ise 1953 yılında Unat ve ark. tarafından saptanmıştır [52]. Toxoplasma gondii seksüel ve aseksüel üreme ile çoğalabilmektedir. Aseksüel üremeyle akut enfeksiyonun gelişmesinde önemli olan haploid (n kromozom sayıl1) takizoitler ile kronik enfeksiyonun gelişiminden sorumlu olan haploid bradizoitler (doku kisti oluşturur) oluşmaktadır. Sadece kedi bağırsak enterositleri içerisinde seksüel üreme ile sporozoit içeren ookistler oluşmaktadır. Seksüel üreme sonucu oluşmuş diploid (2n kromozom sayılı) ookistler dışkı ile atıldıktan sonra sporogoni aşamasında mayoz bölünme geçirerek enfektif haploid sporozoitleri oluşturmaktadır. Daha sonra enfekte olan konaklarda, ookistlerdeki sporozoitler takizotilere, takizoitler ise konak im- 
mun sisteminden korunmak amaciyla bradizoitlere dönüşerek doku kistlerini oluşturmaktadırlar. Kesin konak kedigillerde, yukarıdaki yaşamsal evre dönüşümü dişında bradizoitler eşeyli üremeyi gerçekleştirecek olan merozoitlere dönüşmektedirler $[23,48]$. Kedigiller dıs ortam koșullarına dirençli enfektif ookistleri dışkı içinde yaydıklarından hastalığın bulaşında anahtar konak kabul edilmektedir [19]. Günümüzde, 17 kedi türünün T. gondii ookistlerini oluşturabildiği belirlenmiştir [16, 40]. Kedi nüfusunun beslenme şekli, ev/sokak kedisi olması gibi faktörler toksoplazmozis seroprevalansinda bölgesel değişkenliklere neden olmaktadır. Dünya geneline bakıldığında evcil kedilerde (Felis catus) seroprevalansın \%30-40 arasında olduğu tahmin edilmektedir [19]. Almanya, Fransa ve İtalya'da yapılan çalışmalarda kedilerde seropozitifliğin \%9-46 arasında değiştiği izlenmiştir. Orta Amerika' da bu oranın \%42-74 arasında değiştiği, Meksika, Brezilya, Şili, Arjantin gibi ülkelerin yer aldığ 1 Güney Amerika'da da \%18-73 arasında olduğu bildirilmektedir [19]. Yine Amerika da yapılan başka bir çalışmada klinik olarak hasta olan kedilerde toksoplazmozis seroprevalans1 \%31,6 (n: 12628) olarak bulunmuştur [39]. Tayvan, Japonya, Bangladeş, Singapur ve Kore gibi Asya ülkelerinde yapılan çalışmalarda seropozitiflik oranı \%8-33 arasında bulunmuştur [17]. Misır ve Etiyopya gibi Afrika ülkelerinde bu oranın \%9197 arasında olduğu belirtilmiştir [17]. Türkiye'de de kedilerde seroprevalans çalışmaları gerçekleştirilmiştir. Ankara'da yapılan bir çalışmada ev ve sokak kedilerinde Sabin-Feldman dye testi ile \%40, indirekt floresan antikor testi ile \%34,3, Niğde'de yap1lan diğer bir çalışmada Sabin-Feldman dye testi ile $\% 76$ oranında seropozitiflik saptanmıştır $[37,45]$. Ankara'da yapılan diğer bir çalışmada Sabin-Feldman dye testi ile \%43 oranında seropozitiflik gözlemlenmiştir [32]. Elazı ̆ bölgesinde yapılan çalışmada ise Sabin-Feldman dye test ile $\% 55$ oranında seropozitiflik bildirilmiştir [2]. Benzer şekilde İzmir sokak kedilerinde yapılan bir seroprevalans çalıșmasında ölmüş ve sağlıklı sokak kedilerinde sırasiyla \%42-48 ve \%33,4-34,4 oranında seropozitiflik tespit edildiği bildirilmiştir [8]. Aynı çalışmada ölmüş sokak kedilerinde toxoplasmosis seroprevalans oranları sağlıklı kedilere göre belirgin șekilde daha yüksek bulunmuştur [8]. Kars ili ve çevresinde ise evde yaşayan kedilerde $T$. gondii açısından seropozitiflik oranı $\% 44,1$ olarak tespit edilmiştir [21].

\section{Kedilerde klinik}

Toxoplasma gondii ile enfekte kedilerde belirgin bir klinik gelişmediği, nadiren enteroepital döngüde bazı problemlerin görülebileceği belirtilmiştir. Deneysel olarak doku kistleri ile ağızdan enfekte edilen kedilerin \%10-20'sinde bir-iki hafta sürebilen ishal gelişebileceği ve bu duruma organizmanın enteroepitel çoğalmasının neden olduğu rapor edilmiştir. Son zamanlarda kedilerde yapılan çalışmalarda eozinofilik fibroz gastritis de tanımlanmıştır [42]. Primer enfeksiyon sonrası takizoitlerin aşırı intraselüler çoğalmasının ölümcül ekstraintestinal toksoplazmozise sebep olabileceği ve enfeksiyonun karaciğer, akciğer, beyin ve pankreatik dokulara da yayılabileceği bildirilmiştir. Kedilerde transplasental bulaşma sonucunda ekstraintestinal toksoplazmozis gelişebileceği, genellikle akciğer veya karaciğer tutuluşuyla ölümle sonuçlanabileceği belirtilmiştir [39]. İmmun sistem bozuklukları bulunan kedilerde yaygın toksoplazmozis geliştiği gözlemlenmiştir [4]. Yaygın toksoplazmozisli kedilerde depresyon, iştahsızlık, ateş, peritoneal sıvı birikimi, sarılık ve nefes darlığı görüldüğü, kronik toksoplazmozisli kedilerde üveit, kutanöz lezyonlar, ateş, kaslarda aşırı hassasiyet, aritmi ile seyreden miyokardit, kilo kaybı, iştahsızlık, felç, ataksi, sarılık, diyare ve nefes darlığ 1 da gelişebileceği bildirilmiştir [39]. Toxoplasma gondii için son konak olan kedilerde genellikle toksoplazmozis kliniği oluşmadığ 1 , fakat kedinin yaşına, tekrar enfeksiyonun gelişmesi ve immunsupresyon durumuna bağlı olarak belirli patolojilerin meydana gelebileceği bildirilmiştir [16]. Dubey ve ark. (2010) tarafindan yapılan başka bir çalışmada, konjenital olarak enfekte edilmiş yeni doğan kedilerde nekroza eşlik eden nötrofil ve makrofaj infiltrasyonunun vücudun çeşitli organlarına yayıldığı rapor edilmiştir. Bu organlar arasında akciğer, karaciğer, kalp, iskelet kası, dil, beyin, spinal kord, göz, adrenal bez ve böbrek bulunmaktadır. Karaciğerde litik hepatoselüler nekroz, hepatoselüler bölge kayıplarına sebep olmaktadır. Portal bölgeler lenfosit, plazma hücresi, makrofaj ve daha az sıklıkta nötrofiller içermektedir. Akciğerlerde tip II pnömositlerde, hiperplazi ve septal kapillerde tıkanmalar gözlenmiştir. Ayrıca alveollerin çok sayıda vakuollenmiş sitoplazmaya sahip makrofaj içerdiği saptanmıştır. Oküler lezyonlar vasküler alan ile sınırlandırılmış ve retinada da bulunmuştur [46]. 
Merkezi sinir sisteminde de benzer şekilde multifokal hafif gliosiz ve hemoraji görülmektedir [14].

\section{Diğer Hayvanlardaki patoloji}

Gebelik sırasında toksoplazmoza yakalanan seronegatif dişi koyunlarda abort meydana gelebilir [13]. Gebeliğin 110. gününden sonra bulaşma meydana gelirse klinik olarak normal ancak $T$. gondii doku kistlerini içeren yavrular meydana gelebilmektedir $[3,6]$. Sonuç olarak koyunlarda gebelik sırasındaki enfeksiyon embriyo ölümü, mumyalaşma, abort, ölü doğum ve neonatal ölümlere yol açabilir [18]. Enfekte fötusların çoğu kuzulama dönemine yakın olarak atılır. Koyunlarda üst üste iki kez abort görülmesi düşük bir olasılıktır ancak koyunlara enterotoksemi aşısı uygulamasının ankiste haldeki $T$. gondii doku kistlerin etkinleşmesine yol açabileceği bildirilmiştir [43]. Bu nedenle koyunlarda T. gondii ookistleriyle çevresel kontaminasyonun, vertikal bulaşmaya göre daha az önem taşıdı ğı gösterilmiştir [7]. Toxoplasma gondii büyük ruminantlarda önemli düzeyde abort ve klinik hastalığa sebep olmaz ve gebe ineklerde deneysel oluşturulan hastalık modelleri haricinde, dokularda etken bulunmasına karşın hastalığa yol açmaz [12,43]. Domuzda pnömoni, ensefalitis ve abortla karakterize bulgular görülebilmektedir [34]. Tüm evcil hayvanlarda interstisyel pnömoni, multifokal hepatik nekroz, lenfadenitis, myokarditis ve nonsupuratif meningoensefalitis görülebilir $[35,40]$.

\section{İnsanlarda Toksoplasmozis}

Ateş, gece terlemesi, karaciğer ve dalak büyümesi, kas ve baş ağrısı görülebilir [47]. Meydana gelen lenfadenopati ilk enfeksiyondan sonra farklı zamanlarda tekrar edebilmektedir [48]. Hodgkin lenfoma'lı hastalar, kollagen vasküler bozukluğu olanlar, organ transplantasyonu yapılanlar, ilaç bağımlıları ve AIDS'li hastalar toksoplazmoz açısından risk grubunda yer alır ve prognoz oldukça kötüdür [15]. Konjenital toksoplazmoz, hamilelik esnasinda enfeksiyonun alınması dışında, latent haldeki enfeksiyonun immun sistemi baskılamasiyla tekrar akut hale gelmesi sonucu etkenin fötusa vertikal yolla bulaşmasından da ileri gelebilir [27]. Gebeliğin ilk 3 aylık döneminde düşük, ikinci üç aylık döneminde erken veya ölü doğum ve anomaliye son üç aylık dönemde ise sağlıklı doğum ancak erken bebek ölümlerine neden olabilir [38].

\section{Toxoplasma gondii Enfeksiyonları ve Davranış Değişiklikleri Arasındaki İlişkiler}

Enfeksiyonlarla psikiyatrik hastalıklar arasında bir ilişki olduğu uzun yıllardan bu yana bilinmektedir. Toxoplasma gondii enfeksiyonu tüm dünya ülkelerinde yaygın seropozitiflik oranına sahiptir ve özellikle koyun, keçi tüketiminin yaygın olduğu Fransa, İngiltere, Avusturya gibi ülkelerde insan nüfusunun hemen yarısının $T$. gondii seropozitif olduğu tahmin edilmektedir [15]. Fransa gibi ülkelerde parazitin görülme sıklığının artması ise pozitifliğin sanitasyon kurallarının yanında çiğ ya da az pişmiş et ile beslenme alışkanlığı ile açıklanmaktadır [33]. Ülkemizin ise çeşitli bölgelerinde yapılan çalışmalar sonucunda T. gondii pozitiflik oranının \%43-85 arasında değiştiği ve batı bölgelerinde bu oranın doğu ve orta Anadolu bölgelerine kıyasla daha düşük olduğu tespit edilmiştir [44,49,51,57,59]. Bununla birlikte, yapılan çalışmalarda şizofren bireylerde $T$. gondii enfeksiyonunun daha fazla gözlendiği rapor edilmiştir $[5,48,50]$. Yine de şizofreni ile T. gondii enfeksiyonu arasında ilişkiye vurgu yapılırken, düşük sosyo-ekonomik ve sosyo-kültürel düzey, özbakımda azalma şizofrenik bireylerin enfeksiyona yatkınlığının artırması yönündeki etkilerinin de göz önünde bulundurulması gerekliliğinin de unutulmamas1 gerektiği vurgulanmaktadır. Toksoplazmozun şizofreni için, tek başına hastalık geliştirici bir etken olmaktan çok, konağa ait faktörlerle (immun sistem, psikiyatrik yatkınlık gibi) etkileşerek önemli bir risk oluşturduğu da öne sürülmektedir [36]. İnsanlarda görülen depresyon, Alzheimer, şizofreni gibi nörolojik hastalıklarda hipokampal bölgede anormal değişiklikler görülmektedir. $\mathrm{Bu}$ nedenle yapılan deneysel çalışmalarda kronik enfekte farelerde hipokampus sınırında perivasküler hücresel infiltrasyon varlığ 1 oldukça önemli kabul edilmektedir [30]. Davranış değişiklikleri ile ilgili olarak, $T$. gondii'nin rodentlerde, özellikle kediye karşı duyarsızlığa neden olduğu öne sürülmüştür. Rodentlerde T. gondii'nin öğrenmeye olumsuz etkisini gösteren çalışma sonuçları da bulunmaktadır [29]. Toxoplasma gondii ile enfekte kemiriciler, kedi idrarından korkmazlar. Kemiricilerin bu kokuyu feromon olarak algılayıp seksüel olarak ilgilerinin arttığına dair çalışmalar mevcuttur [54].

Dopamin (DA), vücutta doğal olarak üretilen bir kimyasaldır. Beyinde dopamin reseptörlerini ak- 
tive ederek nörotransmiter olarak görev yapar. Dopamin ayrica hipotalamustan da salgilanır ve kana karışarak nörohormon görevi yapar. Nörohormon olarak görevi hipofizin ön lobundan prolaktin salgılanmasını baskılamaktır. Dopamin dikkat, bağımlılık gibi davranışları ayarlamakta ve hormonal düzenlemelerde fizyolojik olarak önemli rol oynamaktadir [9]. Toxoplasma gondii serebral hemisferler, bazal gangliyonlar, serebellum ve beyin sapı başta olmak üzere merkezi sinir sistemi üzerine güçlü bir tropizm gösterir. Nöropatolojik çalışmalarda T. gondii'nin nöronlar, glial hücreler ve özellikle astrositler üzerine invitro selektif etkisi olduğu gösterilmiştir. Postmortem çalışmalarda şizofrenili hastaların beyinlerinde glial anormalliklerin mevcut olduğu ve özellikle astrositlerin sayısında azalma olduğu tespit edilmiştir [10]. Toxoplasma gondii'nin merkezi sinir sistemi üzerine bir diğer etkisi nörotransmitter yolağında yaptığı değişikliklerdir. Bu zorunlu hücre içi parazit dopamin, norepinefrin ve diğer nörotransmitter sentezini etkilemektedir $[25,56]$. Şizofreni hastalarında da özellikle dopamin, glutamat ve gamma aminobutirik asit gibi nörotransmitterler anormal düzeyde seyrederler [60]. Bir çalışmada, toksoplazma enfeksiyonu ile dopamin artışının arkasındaki mekanizmanın tam olarak bilinmemesine rağmen, interlökin-2 gibi sitokinlerin artışına bağ11 inflamatuar yanıt olarak dopaminin salınabildiğ $i$ vurgulanmıştır [55]. Toksoplasma enfeksiyonu sırasinda astrositler aktive olarak beyinde kinurenik asit üretimini arttırmaktadır. Beyinde artmış kinurenik asit seviyesi glutamin ve nikotin nörotransmitter reseptörlerini inhibe etmekte ve bunun da şizofrenideki kognitif semptomlara neden olduğuna inanılmaktadır [1]. Yapılan bir çalışmada T. gondii'nin katekolamin metabolizmasında anormalliklere neden olduğu ve bunun enfekte kemirgenlerde gözlenen psikolojik ve motor değişikliklerin nedeni olabileceği vurgulanmıştır [60].

Serotonin beyin sapında bulunan Raphe çekirdeği tarafından üretilen bir nörotransmitterdir. Birçok çalışmada serotoninin morfogenez, glial hücrelerin çoğalması, nöronal farklılaşma ve bağlantıların oluşmasında rol aldığı gösterilmiştir [24]. Serotonin diğer sistemlerin nörotransmitter salg1lamalarını kontrol ederek değişik mizaç durumlar1, duygu durum, anksiyete, düşünce, oryantasyon, iştah, hiddet, dürtü (impuls) kontrolü ve seksüel aktivitenin düzenlenmesinde etkili olup üretimi ve metabolizmasındaki değişiklikler bir çok farklı davranışların ortaya çıkmasıyla ilişkilendirilmektedir [31,58]. Depresyon, anksiyete, sosyal fobi, şizofreni, obsesif kompulsif şiddet ve saldırganlık, yeme bozuklukları, bulantı ve kusma gibi birçok bozukluğun etiyolojisinde serotonin yer aldığ dirilmiştir. Serotoninin (5-hidroksitriptamin, 5-HT) dürtü kontrolüyle yakından ilgili olduğu yapılan araştırmalarda ortaya konmuştur. Beyindeki serotonin düzeylerindeki azalmanın davranışın inhibisyonunu azalttığı belirtilmiștir. Yapılan deneysel çalıșmalar sonucunda ise beyinde serotonin eksikliğinin dürtüsel seçimlerin artışına yol açtığ 1 bildirilmiştir. Bunun aksine serotonin düzeyinin arttırılması ise dürtüsel seçim yapma davranışının azalmasına neden olmaktadır [31,53]. Parazitin etkilediği bir diğer yol triptofan metabolik yoludur. Triptofan esansiyel bir aminoasit olup serotonin ve melatonin gibi nörokimyasal medyatörlerin öncülüdür. Toxoplasma gondii'nin takizoid evresinde replikasyonun sağlanması için bu aminoasite gereksinim vardır [22]. Son çalışmalarda T. gondii genomunda, beyinde dopamin sentezinde hiz kisitlayıc enzim olan tirozin hidroksilazı kodlayan iki gen mevcut olduğu bildirilmiştir. Bu bulgular, toksoplazmanın dopamin ve serotonin üzerine etkisi ile konak davranışında değișiklik yapabileceğini desteklemektedir [26]. Öte yandan farelerde kronik $T$. gondii enfeksiyonun reaktivasyonu sonucunda dişi $\mathrm{BALB} / \mathrm{c}$ farelerinde davranışsal değişiklerin saptandığ 1 en son çalışmada $T$. gondii enfeksiyonun reaktivasyon aşamasında triptofan katabolik şantın ve serotonin düzeylerinin tersine değişmesinin depresyon-benzeri davranışa neden olduğu kanıtlanmıştır [41].

\section{Sonuç}

1953 yılından günümüze kadar yapılan çalışmalar Toksoplasma enfeksiyonunun şizofreni gelişiminde anlamlı risk faktörü olduğunu güçlü bir şekilde desteklemektedir. Ayrıca antipsikotikler üzerine yapılan çalışmalar $T$. gondii üzerinde etkili olan azitromisin, trimetoprim sulfametaksazol ve primetamin sulfadiazin gibi antibiyotiklerin şizofreni tedavisinde yararlı olabilme olasılığını düșündürmektedir. $\mathrm{Bu}$ konuda daha çok çalışma yapılması, hem toksoplazmozis hem de şizofreni tedavisi için potansiyel yeni tedavi kombinasyonları ve tedavi modelleri geliştirilmesinde yol gösterici olacaktır. 
İnsanlarda davranış değişiklikleri ile toksoplazmozis arasındaki ilişkiyi irdeleyen çalışmalar oldukça yeni olmakla beraber enfeksiyon için ara ve son konak olan kedilerde parazitin benzer değişiklikler yapıp yapmadığ 1 henüz araştırılmış bir konu değildir. İnsanlarda parazitin yaratmış olduğu problemler açıkça bilinmektedir. Bununla birlikte kedilerde parazitin beyin, spinal kord, göz, akciğer, karaciğer, kalp, iskelet kası, dil, adrenal bez ve böbrek gibi hayati organlarda lezyonlar şekillendirdiği ortaya konulmuştur. Ancak, parazitin kedilerde davranışsal değişikliğe neden olup olmadığı incelenmemiştir.

Sonuç olarak sunulan bu derleme ile $T$. gondii'nin kedilerde insanlardakine benzer davranışsal değişikliklere neden olup olmadığının araştırılması konusuna katkı sunacağı kanaatindeyiz.

\section{Kaynaklar}

1. Arias I, Sorlozano A, Villegas E, (2012). Infectious agents associated with schizophrenia: a meta-analysis. Schizophr Res. 136, 128-136.

2. Babür C, Aktaş M, Dumanlı N, Attaş MG, (1998). Elazı̆̆ yöresinde kedilerde sabin-feldman boya testi ile Antitoxoplasma gondii antikorlarinin araştırılması. Türkiye Klinikleri J Vet Sci.14, 55-58.

3. Baszler TY, Dubey JP, Löhr CV, Foreyt WJ, (2000). Toxoplasmic encephalitis in a free-ranging rocky Mountain bighorn sheep from Washington. J Wildl Dis. 36(4), 752754.

4. Beatty J, Barrs, V, (2003). Acute toxoplasmosis in two cats on cyclosporine therapy. Aust Vet J. 81, 339.

5. Brown SA, (2008). The risk for schizophrenia from childhood and adult infections. Am J Psychiatry. 165, 7-10.

6. Buxton D, (1990). Ovine Toxoplasmosis: A Review. J Roy Soc Med. 83(8), 509-511.

7. Buxton D, Rodger SM, Marley SM, Wright SE, (2006). Toxoplasmosis: The possibilitiy of vertical transmission. Small Ruminant Research. 62, 43-46.

8. Can H, (2014). İzmir sokak kedilerinde toxoplasmosis: Toxoplasma gondii suşlarının Mikrosatellit genotiplendirilmesi ve Toxoplasmosis seroprevalans1. Doktora tezi, Ege Üniversitesi, Sağlık Bilimleri Enstitüsü, İzmir.

9. Çelik G, Tahiroğlu A, Avcı A, (2008). Ergenlik döneminde beynin yapısal ve nörokimyasal değișimi. Klinik Psikiyatri. 11, 42-47.

10. Çetinkaya Z, Yazar S, Gecici O, Namli MN, (2007). AntiToxoplasma gondii antibodies in patients with schi-zophrenia-preliminary findings in a Turkish sample. Schizophr Bull. 33, 789-791.

11. Değirmenci A, (2009). Toxoplasma gondii canlı takizoit üretiminde fare kullanımına alternatif: sürekli hücre kültürü. Doktora tezi, Ege Üniversitesi, Sağlık Bilimleri Enstitüsü, İzmir.
12. Dubey JP, (1986). A Review of Toxoplasmosis in cattle. Vet Par. 22, 177-202.

13. Dubey JP, (1987). Serodiagnosis of postnatally and prenatally induced Toxoplasmosis in sheep. AJVR. 48(8), 12391243.

14. Dubey JP, Mattix ME, Lipscomb TP, (1996). Lesions of neonatally induced toxoplasmosis in cats. Vet Pathol. 33(3), 290-295.

15. Dubey JP, (2010). Toxoplasmosis of Animals and Man. Second Edition, CRC Pres, New York.

16. Dubey JP, Prowell M, (2013). Ante-mortem diagnosis, diarrhea, oocyst shedding, treatment, isolation, and genetic typing of Toxoplasma gondii associated with clinical toxoplasmosis in a naturally infected cat. J Parasitol. 99(1), 158160 .

17. Dubey JP, Darrington C, Tiao N, Ferreira LR, Choudhary S, Molla B, Saville WJ, Tilahun G, Kwok OC, Gebreyes WA, (2013). Isolation of viable Toxoplasma gondii from tissues and feces of cats from Addis Ababa, Ethiopia. J Parasitol. 99(1), 56-58.

18. Duru SY,Kul O, (2016). Toksoplazmozis. J Vet Sci Intern Med-Special Topics 2(1), 58-62.

19. Elmore SA, Jones JL, Conrad PA, Patton S, Lindsay DS, Dubey JP, (2010). Toxoplasma gondii: epidemiology, feline clinical aspects, and prevention. Trends Parasitol. 26(4), 190-196.

20. Epiphanio S, Sinhorini IL, Catao-Dias JL, (2003). Pathology of Toxoplasmosis in captive new world primates. J Comp Pathol. 129, 196-204.

21. Erkılıç EE, Mor N, Babür C, Kırmızıgül AH, Beyhan YE, (2016). The Seroprevalence of Toxoplasma gondii in Cats from the Kars Region, Turkey. Isr J Vet Med. 71(3), 31-35.

22. Fabiani S, Pinto B, Bruschi F, (2013). Toxoplasmosis and neuropsychiatric diseases: can serological studies establish a clear relationship? Neurol Sci. 34, 417-425.

23. Ferguson DJ, (2004). Use of molecular and ultrastructural markers to evaluate stage conversion of Toxoplasma gondii in both the intermediate and definitive host. Int J Parasitol. 34(3), 347-360.

24. Fiş NP, Berkem M, (2009). Nörotransmitter sistemlerinin gelişimi ve psikopatolojiye yansımaları. KPB. 19, 312-321.

25. Flegr J, (2013). Influence of latent toxoplasma infection on human personality, physiology and morphology: pros and cons of the toxoplasma-human model in studying the manipulation hypothesis. J Exp Biol. 216, 127-133.

26. Hamidinejat H, Ghorbanpoor M, Hosseini H, (2010). Toxoplasma gondii infection in first-episode and inpatient individuals with schizophrenia. Int J Infect Dis. 14, 978981

27. Harma M, Gungen N, Demir N, (2004). Toxoplasmosis in pregnant woman in Sanliurfa, South eastern Anatolia city in Turkey. J Egypt Soc Parasitol. 34, 519-525.

28. Hazıroğlu R, Altınsaat S, Atasever A, Akın G, (1988) Kedilerde fatal Toksoplazmozis. Ankara Üniv Vet Fak Derg. 35(2-3), 330-340. 
29. Hazıroğlu R, (1993). An ultrastructural study of Toxoplasma gondii developmental stages in the lungs of the Cat. Isr $\mathrm{J}$ Vet Med. 48, 65-68.

30. Hermes G, Ajioka WJ, Kelly AK, Mui E, Roberts F, Kasza K, Mayr T, Kirisits MJ, Wollmann R, Ferguson JPD, Roberts CW, Hwang JH, Trendler T, Kennan R, Suzuki Y, Reardon C, Hickey WF, Chen L, Mcleod R, (2008). Neurological and behavioral abnormalities, ventricular dilatation, altered cellular functions, inflammation, and neuronal injury in brains of mice due to common, persistent, parasitic infection. J Neuroinflammation. 5-48.

31. Işıloğlu B, (2006). Anksiyete ve depresyon tanısı ile izlenen evli kadınlarda aile içi şiddetin sosyodemografik faktörler, çift uyumu ve hastalıkla ilişkisi. Uzmanlık Tezi, T.C Sağlık Bakanlığı Bakırköy Prof. Dr. Mahzar Osman Ruh Sağlığ1 ve Sinir Hastalıkları Eğitim ve Araştırma Hastanesi 12. Psikiyatri Birimi, İstanbul.

32. İnci A, Budak C, Dinçer Ş, (1996). Ankara'da kedilerde Sabin-Feldman boya testi İle anti-Toxoplasma gondii antikorlarımn araştırılması. T Parazitol Derg. 20(3-4), 407-411.

33. Jeannel D, Niel G, Costagliola D, Danis M, Traore BM, Gentilini M, (1988). Epidemiology of toxoplasmosis among pregnant women in the Paris area. Int J Epidemiol. 17, 595-602.

34. Jones TC, Hunt RD, King NW, (1996). Toxoplasmosis. In: Veterinary Pathology $6^{\text {th }}$ Copyright by Williams and Wilkins. USA, p: 521-555.

35. Jubb KVF, Keneddy PC, Palmer N, (2007). Pathology of Domestic Animals. $5^{\text {th }}$ Edition Vol. 2, California: Academic Press. p: 308-310.

36. Karabulut N, (2013). Toksoplazma ve Şizofreni. Türk Mikrobiyol Cem Derg. 43(2), 39-44.

37. Karatepe B, Babür C, Karatepe M, Kiliç S, Dündar B, (2008). Prevalence of Toxoplasma gondii antibodies and intestinal parasites in stray cats from Nigde, Turkey. Ital J Anim Sci. 7, 113-118

38. Kravetz JD, Federman DG, (2005). Toxoplasmosis in pregnancy. Am J Med. 118(3), 212-216.

39. Lappin MR, (2010). Update on the diagnosis and management of Toxoplasma gondii infection in cats. Topics in Compan An Med. 25(3), 136-141.

40. Lukesova D, Literák I, (1998). Shedding of Toxoplasma gondii oocysts by Felidae in zoos in the Czech Republic. Vet Par. 74, 1-7.

41. Mahmoud ME, Ihara F, Fereig RM, Nishimura $M$, Nishikawa Y, (2016). Induction of depression-related behaviors by reactivation of chronic Toxoplasma gondii infection in mice. Behav Brain Res. 298, 125-133.

42. McConnell JF, Sparkes AH, Blunden AS, Neath PJ, Sansom J, (2007). Eosinophilic fibrosing gastritis and toxoplasmosis in a cat. JFMS. $9(1), 82-88$.

43. Milli ÜH, Hazıroğlu R, (2000). Veteriner Patoloji. Medipress, Malatya.

44. Ocak S, Zeteroglu S, Ozer C, Dolapcioglu K, Gungoren A, (2007). Seroprevalence of Toxoplasma gondii, rubella and cytomegalovirus among pregnant women in southern Turkey. Scan J of Infec Diseases. 39, 231-234.
45. Özkan AT, Çelebi B, Babür C, Lucio-Forster A, Bowman DD, Lindsay DS, (2008). Investigation of anti-Toxoplasma gondii antibodies in cats of the Ankara region of Turkey using the Sabin-Feldman dye test and an indirect fluorescent antibody test. J Parasitol. 94(4), 817-820.

46. Paul M, (1999). Immunoglobulin G avidity in diagnosis of Toxoplasmic lymphadenopathy and ocular Toxoplasmosis. Clin Diagn Lab Immunol. 514-518.

47. Schwartzman JD, (2001). Toxoplasmosis. Gillespie SH, Pearson RD. eds. Principles and Practice of Clinical Parasitology. p. 113-138.

48. Sibley LD, Asis K, James WA, Rosenthal BM, (2011). Genetic diversity of Toxoplasma gondii in animals and humans. Phil Trans Biol Sci. 364(1530), 2749-2761.

49. Tamer GS, Dundar D, Caliskan E, (2009). Seroprevalence of Toxoplasma gondii, rubella and cytomegalovirus among pregnant women in western region of Turkey. Clin Invest Med. 32(1), 43-47.

50. Tanyüksel M, Uzun Ö, Araz E, Koru Ö, Babür C, (2010). Possible role of toxoplasmosis in patients with first-episode schizophrenia. Turk J Med Sci. 40(3), 399-404.

51. Tekay F, Özbek E, (2007). The seroprevalence of Toxoplasma gondii in women from Sanlıurfa a province with high a raw meatball consumption. T Parazitol Derg. 3, 176-179.

52. Unat EK, (1983). Toxoplasma gondii'nin ve Toksoplazmozis'in tarihçesi: Toksoplazmosis. T Parazitol Derg. 3, 1-8.

53. Uzbay T, (2004). Anksiyete ve depresyonun nörobiyolojisi. Klinik Psikiyatri. Ek 4, 3-11.

54. Vyas A, Kim SK, Giacomini N, Boothroyd JC, Sapolsky RM, (2007). Behavioral changes induced by Toxoplasma infection of rodents are highly specific to aversion of cat odors. Neuroscience. 104(15), 6442-6447.

55. Wang T, Tang ZH, Li JF, Li XN, Wang X, Zhao ZJ, (2013). A potential association between Toxoplasma gondii infection and schizophrenia in mouse models. Exp Parasitol. $135,497-502$.

56. Webster JP, Lamberton PHL, Donnelly CA, Torrey EF, (2006). Parasites as causative agents of human affective disorders? The impact of anti-psychotic, mood-stabilizer and anti-parasite medication on Toxoplasma gondii's ability to alter host behaviour. Proc Biol Sci. 273, 1023-1030.

57. Yazar S, Altunoluk B, Akman AA, Sahin I, (2000). Investigation of anti-Toxoplasma gondii antibodies in women during pregnancy. T Parazitol Derg. 24, 343-345.

58. Yazıc1 K, Yazıc1 AE, (2010). Dürtüselliğin nöroanatomik ve nörokimyasal. Psikiyatride Güncel Yaklaşımlar. 2(2), 254 280.

59. Y1lmazer M, Altindis M, Cevrioglu S, (2004). Toxoplasma, cytomegalovirus, rubella, hepatitis $\mathrm{B}$ and hepatitis $\mathrm{C}$ seropositivity rates in pregnant women who live in Afyon region. The Medical Journal of Kocatepe. 5, 49-53.

60. Yolken RH, Dickerson FB, Fuller TE, (2009). Toxoplasma and schizophrenia. Parasite Immunol. 31, 706-715. 